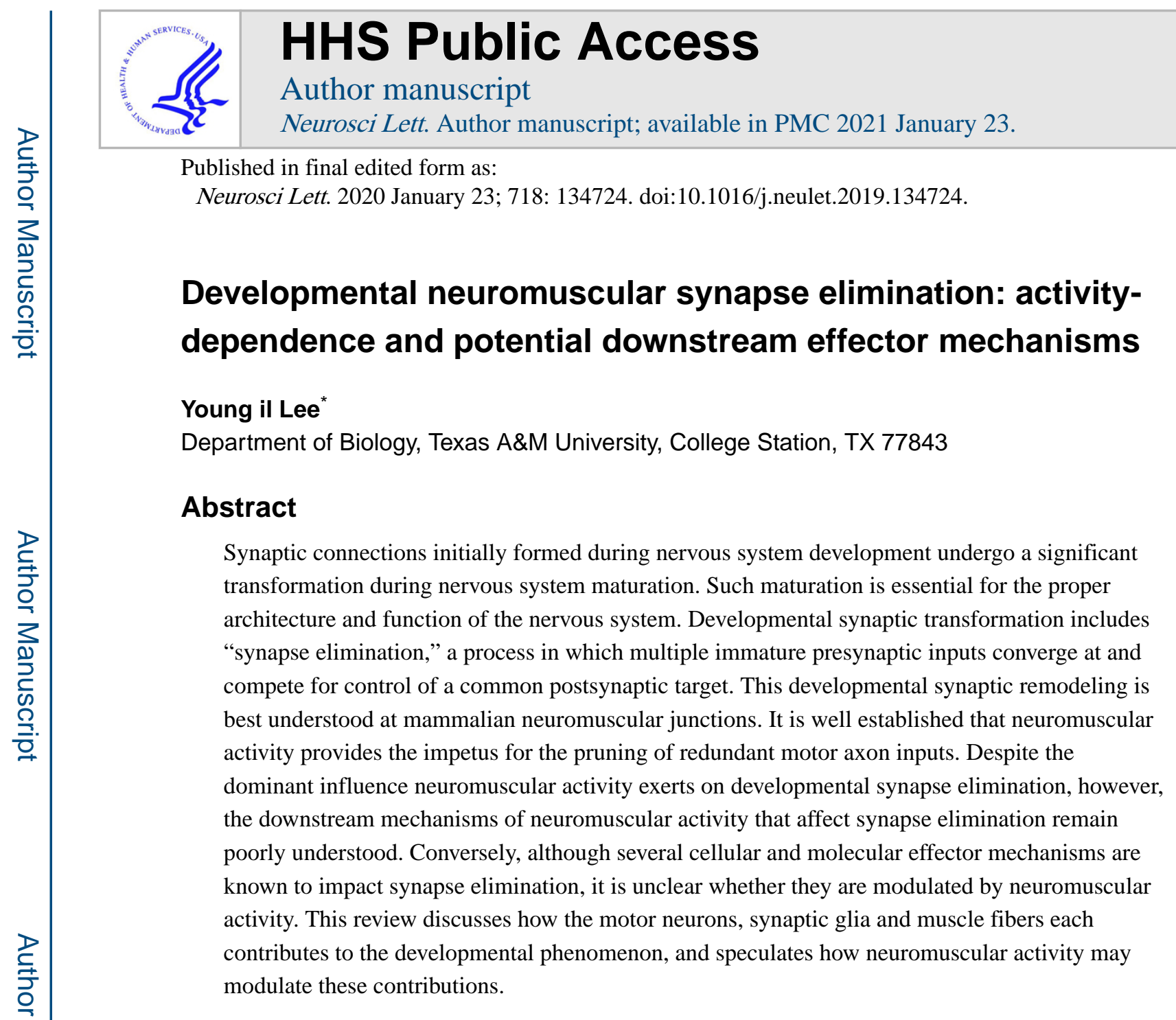

Keywords

Neuromuscular junction; Synapse elimination; Neuromuscular activity; Schwann cells; Muscle fiber types

\title{
Introduction
}

During postnatal maturation, a significant fraction of the initially over-abundant synaptic connections is pruned throughout both central and peripheral nervous systems (CNS and PNS, respectively) [5, 17, 29, 31, 44, 48, 59]. Developmental synapse elimination, a cellular process in which redundant immature synaptic connections no longer required in mature nervous systems are removed, is essential for proper wiring and function of a mature

\footnotetext{
*Correspondence: Department of Biology, Texas A\&M University, 3474 TAMU, College Station, TX, 77843, ylee@ bio.tamu.edu. Publisher's Disclaimer: This is a PDF file of an unedited manuscript that has been accepted for publication. As a service to our customers we are providing this early version of the manuscript. The manuscript will undergo copyediting, typesetting, and review of the resulting proof before it is published in its final form. Please note that during the production process errors may be discovered which could affect the content, and all legal disclaimers that apply to the journal pertain.

Competing interests

The author declares no competing interests.
} 
nervous system. The critical importance of this developmental process is evidenced by a growing body of literature that implicates the contribution of synapses elimination in the CNS (and continued activity-driven synapse remodeling) to learning and memory [25, 37, 81], and its defects to the genesis of various neurodevelopmental and neuropsychiatric disorders $[38,50,84]$.

Many recent studies describe novel and mechanistic insights to the process of developmental synapse elimination in various regions of the CNS - including the cerebellum, the hippocampus and the lateral geniculate nucleus $[10,39,54]$. The reader is referred to many excellent reviews that treat developmental CNS synapse elimination in greater detail [13, 33, 34, 84]. Developmental synapse elimination, however, is most extensively studied and best understood at developing rodent neuromuscular junctions (NMJs). The accumulation of effort and current understanding of developmental neuromuscular synapse elimination - the topic of the current review - stem from several key properties that make the NMJ an ideal preparation for early investigations [86]: its peripheral location (which increases its accessibility compared to CNS synapses), simple architecture (single site of innervation for each muscle fiber), large size (orders of magnitude greater than those formed in the CNS amongst neurons), unambiguous functional readout in the form of muscle contraction in response to presynaptic (nerve) stimulation, and the early identification of the neurotransmitter (acetylcholine; ACh). The availability of biological reagents that allow specific labeling synaptic structures and/or modulate synaptic transmission, including abungarotoxin (a-BTX) and d-tubocurare, makes the NMJ an attractive model synapse. Shared features of developmental synapse elimination, such as dependence on synaptic activity and the involvement of glia and cell recognition molecules, render findings at NMJs pertinent to understanding the parallel processes that occur in CNS.

Innervation of individual muscle fibers in immature animals by multiple motor axons was initially described anatomically more than a century ago by Tello [75], a student of Ramon y Cajal. A functional observation (and "rediscovery") of such polyneuronal innervation in neonatal rodent muscle fibers was produced nearly seven decades later through intracellular recordings of neonatal muscle fibers [61]. The endowment of multiple presynaptic inputs at the NMJ of every muscle fiber at birth is likely to have resulted from an effort by the developing nervous system to ensure innervation - and, consequently, proper development of every nascent muscle fiber. In rodents, polyneuronal innervation of muscle fibers is lost during the first three weeks of postnatal growth and maturation. Through a successive removal of each of the redundant presynaptic motor inputs, every muscle fiber is innervated by a single motor axon. The number of motor neurons and their target muscle fibers remain unchanged during synapse elimination, indicating that the process proceeds by pruning only the local branches of motor axons [1, 5, 35]. The non-overlapping, single innervation of each muscle fiber is necessary for the orderly recruitment of motor units (a motor neuron and the collection of muscle fibers it innervates) during force generation [28].

Developmental neuromuscular synapse elimination is multi-factorial: multiple experimental manipulations impact the timing and outcome of neuromuscular synapse elimination. Despite the current wealth of information derived from nearly five decades of research, there are still noticeable gaps in our understanding of this developmental phenomenon. This 
current article is not meant to be a comprehensive or exhaustive review of the literature on developmental neuromuscular synapse elimination. Moreover, discussion is limited to observations made during early postnatal stages and does not include studies of synapse elimination that occur in adult muscles following injury-induced denervation and subsequent reinnervation of motor endplates by multiple motor axons. A more thorough review of the literature may be found elsewhere $[45,51,85]$. This article is meant to (1) summarize how the motor neurons, synaptic glia and muscle fibers are known to contribute to the developmental phenomenon and (2) speculate how the synapse modifying cellular activities may be regulated.

\section{Neuromuscular activity}

That motor neuron electrical activity exerts a powerful influence on developmental synapse elimination is well established. This parallels the experimental findings that demonstrate CNS synapse elimination is dependent on neural activity, including the proper segregation of retinal ganglion cell terminals within the lateral geniculate nucleus of the visual system [65]. Thompson, Kuffler and Jansen were the first to demonstrate that "a block of impulse conduction in motor nerves interferes with the processes which lead to the establishment of the mature pattern of innervation" within skeletal muscles [79]. Neuromuscular blockade both pre- and postsynaptic using botulinum and a-BTX, respectively - similarly delays the completion of synapse elimination $[4,9]$. Conversely, polyneuronal innervation was eliminated more rapidly when the activity of innervating axons was increased via electrical stimulation [53]. These and a number of additional studies reviewed elsewhere [19, 85] provided ample support for the central role neuromuscular activity/use plays during the removal of supernumerary motor inputs. The questioned remained, however: how does neuromuscular activity influence synapse elimination?

Surgically reducing the number of motor axons that innervate a muscle during the period of synapse elimination leads to the remaining motor axons innervating a greater number of muscle fibers than would without any experimental interventions $[23,78]$. These findings are consistent with the idea that the elimination of extra motor inputs from developing NMJs necessitates an active competition amongst the convergent motor axons at individual endplates. Walsh and Lichtman [83] demonstrated, via repeated vital imaging of developing NMJs in living animals, such competition between motor axons during the final phase of synapse elimination. The eventual winner overtakes the postsynaptic acetylcholine receptor (AChR)-rich surface relinquished by the losing axon for the sole control of the NMJ. On the other hand, selective and chronic stimulation of a subset of motor units results in the stimulated motor neurons innervating more muscle fibers than normal, at the expense of the non-stimulated motor units that innervate the same target muscle [62]. This observation further supports there is active competition between axon terminals converging on common target muscle fibers, and also suggests that more active axons possess an advantage. Inducible-inactivation of the gene that encodes choline acetyltransferase (ChAT; the enzyme responsible for the synthesis of the neurotransmitter $\mathrm{ACh}$ ) produces mice in which varying subsets of motor neurons are silenced [6]. In the resulting mosaic ChAT mice, a silent motor axon terminal persists only if all others in direct competition at the same developing endplate have also been rendered silent. ChAT-inactivated motor neurons are otherwise 
removed from other endplates by active, and thus more competitive, motor axons. The persistence of polyneuronally innervated muscle fibers where all of the motor inputs were rendered inactive further indicates that relative activity among competing axons, rather than their absolute ability (or inability) to elicit postsynaptic responses, helps determine the relative competitiveness of each convergent axon.

Patterns, in addition to the abundance, of action potential activity emitted by competing motor axons is another evidently important factor. Developmental neuromuscular synapse elimination can occur despite surprisingly low overall activity. About half of the muscle fibers achieve single innervation by postnatal day (P) 9 in mouse soleus muscles even when innervating motor neurons of wake, behaving animals fire at a median frequency of less than $1 \mathrm{~Hz}$ [55] (activation frequencies of $\sim 10-25 \mathrm{~Hz}$ have been reported for neonatal rats [7, 20]). The temporal relationship of the activities within a pool of competing motor neurons as well as the intrinsic discharge patterns of individual motor neurons (and thus activity pattern of motor units) contribute significantly to the elimination of redundant inputs at developing NMJs. Personius and Balice-Gordon [55] found that, within the mouse soleus muscle, activities of about $67 \%$ of motor units temporally correlated with at least one other motor unit at P2 while only about $10 \%$ of motor units displayed temporally correlated activity during the second postnatal week, and none during the third week. These findings are in good agreement with a similar study performed using developing rat muscles by Cangiano and his colleagues [7] who further determined that pruning of redundant motor inputs necessitates at least a 25-ms offset in spikes produced by competing axons [21]. The postnatal appearance of divergent motor neuron spike timing apparently allows the postnatal muscle fibers to discriminate between a number of presynaptic inputs, and maintain/ strengthen the inputs able to produce coincident contractions in a Hebbian fashion (Fig. 1). The postnatal switch to asynchronized motor unit activity appears co-incident with diminution of electrical coupling of motor neurons in the spinal cord and results, at least partly, from a developmental decline in the expression of connexin proteins responsible for producing gap junctions $[12,56]$. Genetic inactivation of one such connexin $(\mathrm{Cx} 40)$ leads to asynchronized motor neuron activity and precocious synapse elimination [56], while persistently elevated expression of connexins in motor neurons leads to prolonged maintenance of synchronized motor unit activity and delays synapse elimination [57]. One may speculate whether glial cells - whose contributions to developmental synapse elimination both in CNS and at NMJs (discussed below) are now well documented [43, 84] - remove gap junctions, and thus also contribute to the gradual reduction of electrical coupling between motor neurons [56].

Thompson [77] demonstrated chronic stimulations of soleus muscles (a muscle with predominantly type I or "slow" twitch muscle fibers), each with an identical number of stimuli, can produce different rates of synapse elimination when presented using distinct spike patterns. Patterns of stimulation meant to mimic activities of "fast" motor neurons accelerated the loss of extra motor inputs, while no such alterations were observed with a pattern that mimicked activities of "slow" motor neurons. Coincidently, this precocious loss of polyneuronal innervation following chronic "fast" stimulation of soleus muscle is accompanied by a shift in contraction characteristics from that of a "slow" muscle to one that resemble a "fast" muscle. These observations appear also to suggest a potential 
relationship between the timing of synapse elimination and contractile properties of the target muscle.

Evidence now indicate that all three cellular components of mammalian NMJs - presynaptic motor axon terminals/branches, non-myelinating glia (terminal Schwann cells; tSCs) and postsynaptic muscle fibers - all actively participate in synapse elimination. The ways in which the components of the NMJ are known to contribute to synapse elimination are discussed in the following sections. Neuromuscular activity likely regulates some, if not all, of the cellular/molecular effectors that impact the outcome of developmental synapse elimination. The downstream effectors through which neuromuscular activity exerts its influence on synapse elimination, however, remain largely unknown. Thus, while it may be tempting to assign activity of motor neurons or the muscular system as the dominant upstream modulator of these effectors, it would be premature in the absence of any direct empirical support.

\section{Terminal Schwann cells}

Recent studies provide a compelling argument for active tSC participation in the competition that underlies developmental synapse elimination. Ultrastructural examination of neonatal NMJs, by Thompson and colleagues, revealed two tSC behaviors not observed at mature singly innervated NMJs: robust phagocytosis of motor axon terminals still in contact with AChR-rich postsynaptic muscle membrane as well as their own affinity for the postsynaptic membrane [42, 69]. These activities appear to promote removal, albeit randomly, of redundant motor axon terminals still in contact with endplates through their (1) consumption (tSC phagocytosis) and (2) physical displacement from postsynaptic AChR-rich membrane by the intrusion of tSC processes into the synaptic cleft (Fig. 2 A,B). Indeed, exaggeration of these tSC behaviors through transgenic overexpression of type-III neuregulin1 (NRG1-III) on motor axons, accelerates the time course of synapse elimination in vivo [42]. Turney and Lichtman [82] put forth an in silico simulation that recapitulates many of the features of synapse elimination previously noted including synaptic segregation [26], a reversal of postsynaptic occupancy where an axon with a smaller territory is the ultimate winner [83], and loss of all but one neuron from many. A central assumption of their simulations was that "maintenance of synaptic contacts is imperfect and that at regular intervals an axon withdraws from an individual synaptic site at random." [82] The study left unaccounted the cause(s) of such random withdrawal and the subsequent takeover of now-vacant postsynaptic sites by any one of the remaining axons whose branches are nearby. The neonatal tSC behaviors - phagocytosis and displacement of axon terminals - provide an explanation of the "random" axon withdrawal that drives the Turney-Lichtman simulations.

It remains undetermined, however, whether the axon terminal-displacing activities of tSCs are modulated by motor neuron activity (Fig. 2B). Such modulation could be done in at least two possible ways that need not be mutually exclusive. NRG1-III transcript levels are increased in cultured CNS neurons in response to increased activity [46]. Similarly, synaptic deposition of a secreted isoform of NRG1 is activity-dependent [47]. One may, thus, imagine a scenario in which motor neuron activity levels regulate axonal expression of the membrane-tethered NRG1-III to elicit subsequent tSC behaviors to promote synapse 
elimination. Direct experimental evidence in support, however, does not yet exist.

Alternatively, motor neuron activity may directly activate tSCs (Fig. 2C). Neonatal tSCs are sensitive to ATP [18], which is stored and released together with ACh from synaptic vesicles of motor axon terminals [68]. Pharmacological inhibition of a purinergic receptor P2Y1R delays neuromuscular synapse elimination [18]. Moreover, tSCs appear able to recognize and respond specifically to the more active of the competing axons at individual synapses [18]. Regardless, cellular/molecular mechanism(s) that lie downstream to this purinergic activation of tSCs and promotes synapse elimination remains undefined. One open possibility is that tSC behaviors - such as their affinity for AChR-rich postsynaptic membrane and phagocytosis of immature axon terminals - are a point of convergence for NRG1-III and ATP signaling pathways (Fig. 2C).

\section{Skeletal muscle fibers}

The profound influence of neuromuscular activity pattern on neuromuscular synapse elimination [77] has raised obvious curiosity about potential influence muscle fiber type may also exert on the developmental phenomenon. Initial inquiries into the subject revealed no distinction in the rates of synapse elimination between fast and slow muscle fibers $[2,16,67$, 71]. A recent study, in contrast, provides evidence of a causal relationship between the fiber type constituency and the rate of synapse elimination of a target muscle [41]. Comparison of muscles with different fiber type makeup (soleus vs. extensor digitorum longus) revealed that a greater fraction of muscle fibers remained polyneuronally innervated in muscles with more type I (or "slow") twitch muscle fibers. In agreement, the soleus muscle of transgenic animals that contained fewer type I "slow" fiber type eliminated polyneuronal innervation earlier (see also [40]). Finally, a direct intramuscular comparison of NMJs situated either on type I or type II ("fast") twitch fibers demonstrated an overall delay in the loss of polyneuronal innervation for type I fibers.

The exchange of signals known to occur between presynaptic nerve terminals and their target muscle fibers as well as tSCs at the NMJs, and the influence both components exert on each other, adds a layer of complexity in determining the contributions of each to synapse elimination. This is especially true when considering the relationship between the rate of synapse elimination and muscle fiber types. As stated above, distinct patterns of neuromuscular use alter both muscle fiber contraction properties $[8,49,77]$ and the rate of synapse elimination [77]. Altered muscle fiber properties, however, need not be a cobyproduct of presynaptic influence. The fact that a muscle fiber-specific genetic manipulation that reduced the number of type I muscle fibers accelerated synapse elimination [41] - together with an apparently normal development of muscle fiber types and their distribution within fetal muscles that had been rendered aneural [14] - argues that muscle fibers are not an indifferent object of competition amongst innervating axons, but actively exert influence during the process. Results of another recent study, whose findings indicate that "fast/slow identity" of postsynaptic muscle fibers can influence that of the innervating motor neurons [11], are consistent with this idea.

Each mature motor unit contains only a single fiber type [36]. This homogeneity of muscle fiber type within a motor unit was long thought to be a product of selective innervation [24, 
27, 80]: axons of a motor neuron seek and synapse with target muscle fibers of appropriate contractile properties. More recent studies [11,22], however, demonstrate a significant degree of fiber type heterogeneity within motor units. Such heterogeneity would be expected following pervasive innervation of target muscles during early development [74] and suggests preferential pruning of motor inputs with incompatible activity patterns during refinement of neuromuscular connections during postnatal maturation. Whether by selective innervation or through nondiscriminant innervation followed by selective pruning of mismatched synaptic partners, either or both of the presynaptic motor axon terminals and postsynaptic muscle fibers must possess the means to discriminate between appropriate and incompatible synaptic partners (Fig. 1). The mechanisms responsible for bringing about the appropriate matching of pre- and postsynaptic partners remain obscure. Molecules that promote maintenance/stability or withdrawal of nerve terminals have been collectively labeled synaptotrophins and synaptotoxins, respectively [64, 70]. A quick survey of the literature reveals several candidate molecules. Class 1 major histocompatibility complex (MHC1) molecules - whose gene inactivations have recently been shown to delay synapse elimination (both at the NMJ and lateral geniculate nucleus of the visual system $[39,76]$ ) could serve as recognition tags for compatible synaptic partners. Ephrin-A3, a repulsive axon guidance molecule, recently found to be expressed specifically by type I (slow) twitch fibers [72], may actively repel immature axons of "fast" motor neurons. Moreover, although the protracted synapse elimination in muscles of neural cell adhesion molecule (NCAM) deficient animals appear to stem from altered presynaptic activity [60], the reported upregulation of NCAM on surface of denervated muscle fibers [15] may be construed as an attempt to provide a more permissive substrate for axons that come to innervate them. Secreted factors present another class of molecules that may be regulated by activity or differentially expressed by muscle fiber types to influence synapse elimination. These include brain-derived neurotrophic factor (BDNF), whose expression and functional maturation are activity-dependent [30, 32], fibroblast growth factor binding protein 1 (FGFBP1) whose absence retards synapse elimination [73], and glial cell line-derived neurotrophic factor (GDNF), whose transgenic overexpression in muscle prolongs the period of synapse elimination [52]. It is presently unclear whether distinct patterns of synaptic activity differently modulate muscle expression of BDNF, FGFBP1, GDNF, MHC1 or NCAM.

\section{Motor neuron}

There are a couple of potential mechanisms via which motor neurons could actively contribute to axon withdrawal during synapse elimination. A recent study demonstrated branch-specific local microtubule severing and disassembly that mediate motor axon branch loss [3]. Pharmacological microtubule stabilization delays neuromuscular stabilization. Mice lacking neurofilament light chain also display delayed neuromuscular synapse elimination [63]. These findings implicate regulation of axonal cytoskeleton in the removal of supernumerary motor axons from NMJs. Genetic inactivation of caspase-3, which fully protects cultured sensory neurons from trophic factor withdrawal-induced axon degeneration, produced a delay in the developmental pruning of retinocollicular axons [66]. These and other mechanisms - active locally within terminal branches of motor neurons, 
therefore, could impact the timing of synapse elimination. These mechanisms, however, are unlikely to act autonomously, but in response to external selection cues or pressures such as the supply of target-derived trophic factor(s) (BDNF and/or GDNF) and hostile tSC behaviors at developing NMJs, both of which may be activity-dependent. In fact, delayed neuromuscular synapse elimination in glial neurofascin (Nfasc155) deficient mice appears to be a product of Schwann cell-mediated modulation of motor axon cytoskeleton [63].

\section{Conclusion}

On the one hand, there has been an identification of a number of cellular and molecular effectors that influence developmental neuromuscular synapse elimination in recent years. In many instances, however, the mode of regulation for these effectors remains unknown. On the other, while neuromuscular activity has long been known to impose its unquestioned influence over the loss of excess motor inputs during development, its downstream effectors remain obscure. One recent finding of note is the unexpected influence of glutamatergic transmission at NMJs on neuromuscular synapse elimination [58]: the rate of synapse elimination correlates with the degree of NMDA receptor activation. This supposedly involves tSC-mediated conversion of $\mathrm{N}$-acetylaspartylglutamate, released from motor nerve terminal, into glutamate, which then binds and activates muscle NMDA receptor to produce $\mathrm{Ca}^{2}+$ influx [58]. It is unclear how this NMDA-mediated pathway, which requires the participation of all three cellular components of NMJs, interacts with neuromuscular activity and pathways that contribute to synapse elimination. One apparent certainty is the need for additional effort in determining the relative contributions of each of the cellular components and the nature of the influence neuromuscular activity imposes on the multitude of effector mechanisms that bring about synapse elimination.

\section{Acknowledgment}

Wesley J. Thompson - who performed many of the pioneering work on neuromuscular synapse elimination cited in this manuscript, and to whom I am deeply indebted for his mentorship, friendship, encouragements and generosity - passed away on $26^{\text {th }}$ of March, 2019. I also thank S.G. Haddix and R.T. Massopust for critical reading of this manuscript. This work was supported by a National Institutes of Health grant to WJT (NS20480) and funds from Texas A\&M University (YL).

\section{References}

[1]. Balice-Gordon RJ, Thompson WJ, Synaptic rearrangements and alterations in motor unit properties in neonatal rat extensor digitorum longus muscle, J Physiol 398 (1988) 191-210. [PubMed: 3392670]

[2]. Bixby JL, van Essen DC, Regional differences in the timing of synapse elimination in skeletal muscles of the neonatal rabbit, Brain Res 169 (1979) 275-286. [PubMed: 445158]

[3]. Brill MS, Kleele T, Ruschkies L, Wang M, Marahori NA, Reuter MS, Hausrat TJ, Weigand E, Fisher M, Ahles A, Engelhardt S, Bishop DL, Kneussel M, Misgeld T, Branch-Specific Microtubule Destabilization Mediates Axon Branch Loss during Neuromuscular Synapse Elimination, Neuron 92 (2016) 845-856. [PubMed: 27773584]

[4]. Brown MC, Holland RL, Hopkins WG, Restoration of focal multiple innervation in rat muscles by transmission block during a critical stage of development, J Physiol 318 (1981) 355-364. [PubMed: 6275069]

[5]. Brown MC, Jansen JK, Van Essen D, Polyneuronal innervation of skeletal muscle in new-born rats and its elimination during maturation, J Physiol 261 (1976) 387-422. [PubMed: 978579] 
[6]. Buffelli M, Burgess RW, Feng G, Lobe CG, Lichtman JW, Sanes JR, Genetic evidence that relative synaptic efficacy biases the outcome of synaptic competition, Nature 424 (2003) 430-434. [PubMed: 12879071]

[7]. Buffelli M, Busetto G, Cangiano L, Cangiano A, Perinatal switch from synchronous to asynchronous activity of motoneurons: link with synapse elimination, Proc Natl Acad Sci U S A 99 (2002) 13200-13205. [PubMed: 12242340]

[8]. Buller AJ, Eccles JC, Eccles RM, Interactions between motoneurones and muscles in respect of the characteristic speeds of their responses, J Physiol 150 (1960) 417-439. [PubMed: 13805874]

[9]. Callaway EM, Van Essen DC, Slowing of synapse elimination by alpha-bungarotoxin superfusion of the neonatal rabbit soleus muscle, Dev Biol 131 (1989) 356-365. [PubMed: 2912800]

[10]. Carrillo J, Nishiyama N, Nishiyama H, Dendritic translocation establishes the winner in cerebellar climbing fiber synapse elimination, J Neurosci 33 (2013) 7641-7653. [PubMed: 23637158]

[11]. Chakkalakal JV, Nishimune H, Ruas JL, Spiegelman BM, Sanes JR, Retrograde influence of muscle fibers on their innervation revealed by a novel marker for slow motoneurons, Development 137 (2010) 3489-3499. [PubMed: 20843861]

[12]. Chang Q, Gonzalez M, Pinter MJ, Balice-Gordon RJ, Gap junctional coupling and patterns of connexin expression among neonatal rat lumbar spinal motor neurons, J Neurosci 19 (1999) 10813-10828. [PubMed: 10594064]

[13]. Chung WS, Allen NJ, Eroglu C, Astrocytes Control Synapse Formation, Function, and Elimination, Cold Spring Harb Perspect Biol 7 (2015) a020370. [PubMed: 25663667]

[14]. Condon K, Silberstein L, Blau HM, Thompson WJ, Differentiation of fiber types in aneural musculature of the prenatal rat hindlimb, Dev Biol 138 (1990) 275-295. [PubMed: 2318339]

[15]. Covault J, Sanes JR, Neural cell adhesion molecule (N-CAM) accumulates in denervated and paralyzed skeletal muscles, Proc Natl Acad Sci U S A 82 (1985) 4544-4548. [PubMed: 3892537]

[16]. Cramer KS, Van Essen DC, Maturation of fast and slow motor units during synapse elimination in the rabbit soleus muscle, Dev Biol 171 (1995) 16-26. [PubMed: 7556893]

[17]. Crepel F, Mariani J, Delhaye-Bouchaud N, Evidence for a multiple innervation of Purkinje cells by climbing fibers in the immature rat cerebellum, J Neurobiol 7 (1976) 567-578. [PubMed: 1003202]

[18]. Darabid H, Arbour D, Robitaille R, Glial cells decipher synaptic competition at the mammalian neuromuscular junction, J Neurosci 33 (2013) 1297-1313. [PubMed: 23345206]

[19]. Darabid H, Perez-Gonzalez AP, Robitaille R, Neuromuscular synaptogenesis: coordinating partners with multiple functions, Nat Rev Neurosci 15 (2014) 703-718. [PubMed: 25493308]

[20]. Eken T, Elder GC, Lomo T, Development of tonic firing behavior in rat soleus muscle, J Neurophysiol 99 (2008) 1899-1905. [PubMed: 18256168]

[21]. Favero M, Busetto G, Cangiano A, Spike timing plays a key role in synapse elimination at the neuromuscular junction, Proc Natl Acad Sci U S A 109 (2012) E1667-1675. [PubMed: 22619332]

[22]. Fladby T, Jansen JK, Development of homogeneous fast and slow motor units in the neonatal mouse soleus muscle, Development 109 (1990) 723-732. [PubMed: 2401222]

[23]. Fladby T, Jansen JK, Postnatal loss of synaptic terminals in the partially denervated mouse soleus muscle, Acta Physiol Scand 129 (1987) 239-246. [PubMed: 3577811]

[24]. Fladby T, Jansen JK, Selective innervation of neonatal fast and slow muscle fibres before net loss of synaptic terminals in the mouse soleus muscle, Acta Physiol Scand 134 (1988) 561-562. [PubMed: 2854944]

[25]. Fu M, Yu X, Lu J, Zuo Y, Repetitive motor learning induces coordinated formation of clustered dendritic spines in vivo, Nature 483 (2012) 92-95. [PubMed: 22343892]

[26]. Gan WB, Lichtman JW, Synaptic segregation at the developing neuromuscular junction, Science 282 (1998) 1508-1511. [PubMed: 9822385]

[27]. Gordon H, Van Essen DC, Specific innervation of muscle fiber types in a developmentally polyinnervated muscle, Dev Biol 111 (1985) 42-50. [PubMed: 3161768] 
[28]. Henneman E, The size-principle: a deterministic output emerges from a set of probabilistic connections, J Exp Biol 115 (1985) 105-112. [PubMed: 3161974]

[29]. Hubel DH, Wiesel TN, LeVay S, Plasticity of ocular dominance columns in monkey striate cortex, Philos Trans R Soc Lond B Biol Sci 278 (1977) 377-409. [PubMed: 19791]

[30]. Hurtado E, Cilleros V, Nadal L, Simo A, Obis T, Garcia N, Santafe MM, Tomas M, Halievski K, Jordan CL, Lanuza MA, Tomas J, Muscle Contraction Regulates BDNF/TrkB Signaling to Modulate Synaptic Function through Presynaptic cPKCalpha and cPKCbetaI, Front Mol Neurosci 10 (2017) 147. [PubMed: 28572757]

[31]. Jackson H, Parks TN, Functional synapse elimination in the developing avian cochlear nucleus with simultaneous reduction in cochlear nerve axon branching, J Neurosci 2 (1982) 1736-1743. [PubMed: 6754881]

[32]. Je HS, Yang F, Ji Y, Potluri S, Fu XQ, Luo ZG, Nagappan G, Chan JP, Hempstead B, Son YJ, Lu $\mathrm{B}$, ProBDNF and mature BDNF as punishment and reward signals for synapse elimination at mouse neuromuscular junctions, J Neurosci 33 (2013) 9957-9962. [PubMed: 23761891]

[33]. Kano M, Hashimoto K, Activity-dependent maturation of climbing fiber to Purkinje cell synapses during postnatal cerebellar development, Cerebellum 11 (2012) 449-450. [PubMed: 22194041]

[34]. Kano M, Watanabe T, Uesaka N, Watanabe M, Multiple Phases of Climbing Fiber Synapse Elimination in the Developing Cerebellum, Cerebellum 17 (2018) 722-734. [PubMed: 30009357]

[35]. Keller-Peck CR, Walsh MK, Gan WB, Feng G, Sanes JR, Lichtman JW, Asynchronous synapse elimination in neonatal motor units: studies using GFP transgenic mice, Neuron 31 (2001) 381394. [PubMed: 11516396]

[36]. Kugelberg E, Adaptive transformation of rat soleus motor units during growth, J Neurol Sci 27 (1976) 269-289. [PubMed: 131182]

[37]. Lai CS, Franke TF, Gan WB, Opposite effects of fear conditioning and extinction on dendritic spine remodelling, Nature 483 (2012) 87-91. [PubMed: 22343895]

[38]. Lee E, Chung WS, Glial Control of Synapse Number in Healthy and Diseased Brain, Front Cell Neurosci 13 (2019) 42. [PubMed: 30814931]

[39]. Lee H, Brott BK, Kirkby LA, Adelson JD, Cheng S, Feller MB, Datwani A, Shatz CJ, Synapse elimination and learning rules co-regulated by MHC class I H2-Db, Nature 509 (2014) 195-200. [PubMed: 24695230]

[40]. Lee Y, Mikesh M, Smith I, Rimer M, Thompson W, Muscles in a mouse model of spinal muscular atrophy show profound defects in neuromuscular development even in the absence of failure in neuromuscular transmission or loss of motor neurons, Dev Biol 356 (2011) 432-444. [PubMed: 21658376]

[41]. Lee YI, Differences in the constituent fiber types contribute to the intermuscular variation in the timing of the developmental synapse elimination, Sci Rep 9 (2019) 8694. [PubMed: 31213646]

[42]. Lee YI, Li Y, Mikesh M, Smith I, Nave KA, Schwab MH, Thompson WJ, Neuregulin1 displayed on motor axons regulates terminal Schwann cell-mediated synapse elimination at developing neuromuscular junctions, Proc Natl Acad Sci U S A 113 (2016) E479-487. [PubMed: 26755586]

[43]. Lee YI, Thompson WJ, Harlow ML, Schwann cells participate in synapse elimination at the developing neuromuscular junction, Curr Opin Neurobiol 47 (2017) 176-181. [PubMed: 29121585]

[44]. Lichtman JW, The reorganization of synaptic connexions in the rat submandibular ganglion during post-natal development, J Physiol 273 (1977) 155-177. [PubMed: 599418]

[45]. Lichtman JW, Colman H, Synapse elimination and indelible memory, Neuron 25 (2000) 269278. [PubMed: 10719884]

[46]. Liu X, Bates R, Yin DM, Shen C, Wang F, Su N, Kirov SA, Luo Y, Wang JZ, Xiong WC, Mei L, Specific regulation of NRG1 isoform expression by neuronal activity, J Neurosci 31 (2011) 8491-8501. [PubMed: 21653853]

[47]. Loeb JA, Hmadcha A, Fischbach GD, Land SJ, Zakarian VL, Neuregulin expression at neuromuscular synapses is modulated by synaptic activity and neurotrophic factors, J Neurosci 22 (2002) 2206-2214. [PubMed: 11896160] 
[48]. Lohof AM, Delhaye-Bouchaud N, Mariani J, Synapse elimination in the central nervous system: functional significance and cellular mechanisms, Rev Neurosci 7 (1996) 85-101. [PubMed: 8819204]

[49]. Lomo T, Westgaard RH, Dahl HA, Contractile properties of muscle: control by pattern of muscle activity in the rat, Proc R Soc Lond B Biol Sci 187 (1974) 99-103. [PubMed: 4153974]

[50]. Neniskyte U, Gross CT, Errant gardeners: glial-cell-dependent synaptic pruning and neurodevelopmental disorders, Nat Rev Neurosci 18 (2017) 658-670. [PubMed: 28931944]

[51]. Nguyen QT, Lichtman JW, Mechanism of synapse disassembly at the developing neuromuscular junction, Curr Opin Neurobiol 6 (1996) 104-112. [PubMed: 8794054]

[52]. Nguyen QT, Parsadanian AS, Snider WD, Lichtman JW, Hyperinnervation of neuromuscular junctions caused by GDNF overexpression in muscle, Science 279 (1998) 1725-1729. [PubMed: 9497292]

[53]. O'Brien RA, Ostberg AJ, Vrbova G, Observations on the elimination of polyneuronal innervation in developing mammalian skeletal muscle, J Physiol 282 (1978) 571-582. [PubMed: 722562]

[54]. Paolicelli RC, Bolasco G, Pagani F, Maggi L, Scianni M, Panzanelli P, Giustetto M, Ferreira TA, Guiducci E, Dumas L, Ragozzino D, Gross CT, Synaptic pruning by microglia is necessary for normal brain development, Science 333 (2011) 1456-1458. [PubMed: 21778362]

[55]. Personius KE, Balice-Gordon RJ, Loss of correlated motor neuron activity during synaptic competition at developing neuromuscular synapses, Neuron 31 (2001) 395-408. [PubMed: 11516397]

[56]. Personius KE, Chang Q, Mentis GZ, O’Donovan MJ, Balice-Gordon RJ, Reduced gap junctional coupling leads to uncorrelated motor neuron firing and precocious neuromuscular synapse elimination, Proc Natl Acad Sci U S A 104 (2007) 11808-11813. [PubMed: 17609378]

[57]. Personius KE, Karnes JL, Parker SD, NMDA receptor blockade maintains correlated motor neuron firing and delays synapse competition at developing neuromuscular junctions, J Neurosci 28 (2008) 8983-8992. [PubMed: 18768692]

[58]. Personius KE, Slusher BS, Udin SB, Neuromuscular NMDA Receptors Modulate Developmental Synapse Elimination, J Neurosci 36 (2016) 8783-8789. [PubMed: 27559162]

[59]. Purves D, Lichtman JW, Elimination of synapses in the developing nervous system, Science 210 (1980) 153-157. [PubMed: 7414326]

[60]. Rafuse VF, Polo-Parada L, Landmesser LT, Structural and functional alterations of neuromuscular junctions in NCAM-deficient mice, J Neurosci 20 (2000) 6529-6539. [PubMed: 10964958]

[61]. Redfern PA, Neuromuscular transmission in new-born rats, J Physiol 209 (1970) 701-709. [PubMed: 5499804]

[62]. Ridge RM, Betz WJ, The effect of selective, chronic stimulation on motor unit size in developing rat muscle, J Neurosci 4 (1984) 2614-2620. [PubMed: 6491726]

[63]. Roche SL, Sherman DL, Dissanayake K, Soucy G, Desmazieres A, Lamont DJ, Peles E, Julien JP, Wishart TM, Ribchester RR, Brophy PJ, Gillingwater TH, Loss of glial neurofascin 155 delays developmental synapse elimination at the neuromuscular junction, J Neurosci 34 (2014) 1290412918. [PubMed: 25232125]

[64]. Sanes JR, Lichtman JW, Development of the vertebrate neuromuscular junction, Annu Rev Neurosci 22 (1999) 389-442. [PubMed: 10202544]

[65]. Shatz CJ, Stryker MP, Prenatal tetrodotoxin infusion blocks segregation of retinogeniculate afferents, Science 242 (1988) 87-89. [PubMed: 3175636]

[66]. Simon DJ, Weimer RM, McLaughlin T, Kallop D, Stanger K, Yang J, O’Leary DD, Hannoush RN, Tessier-Lavigne M, A caspase cascade regulating developmental axon degeneration, J Neurosci 32 (2012) 17540-17553. [PubMed: 23223278]

[67]. Slater CR, Postnatal maturation of nerve-muscle junctions in hindlimb muscles of the mouse, Dev Biol 94 (1982) 11-22. [PubMed: 7152099]

[68]. Smith DO, Sources of adenosine released during neuromuscular transmission in the rat, J Physiol 432 (1991) 343-354. [PubMed: 1653323] 
[69]. Smith IW, Mikesh M, Lee Y, Thompson WJ, Terminal Schwann cells participate in the competition underlying neuromuscular synapse elimination, J Neurosci 33 (2013) 17724-17736. [PubMed: 24198364]

[70]. Snider WD, Lichtman JW, Are neurotrophins synaptotrophins?, Mol Cell Neurosci 7 (1996) 433442. [PubMed: 8875427]

[71]. Soha JM, Yo C, Van Essen DC, Synapse elimination by fiber type and maturational state in rabbit soleus muscle, Dev Biol 123 (1987) 136-144. [PubMed: 3622925]

[72]. Stark DA, Coffey NJ, Pancoast HR, Arnold LL, Walker JP, Vallee J, Robitaille R, Garcia ML, Cornelison DD, Ephrin-A3 promotes and maintains slow muscle fiber identity during postnatal development and reinnervation, J Cell Biol 211 (2015) 1077-1091. [PubMed: 26644518]

[73]. Taetzsch T, Tenga MJ, Valdez G, Muscle Fibers Secrete FGFBP1 to Slow Degeneration of Neuromuscular Synapses during Aging and Progression of ALS, J Neurosci 37 (2017) 70-82. [PubMed: 28053031]

[74]. Tapia JC, Wylie JD, Kasthuri N, Hayworth KJ, Schalek R, Berger DR, Guatimosim C, Seung HS, Lichtman JW, Pervasive synaptic branch removal in the mammalian neuromuscular system at birth, Neuron 74 (2012) 816-829. [PubMed: 22681687]

[75]. Tello F, Degeneration et regeneration des plagues motrices, Travaux du Laboratorire de Recherches Biologiques de l'Universit'e de Madrid 5 (1907) 117-149.

[76]. Tetruashvily MM, McDonald MA, Frietze KK, Boulanger LM, MHCI promotes developmental synapse elimination and aging-related synapse loss at the vertebrate neuromuscular junction, Brain Behav Immun 56 (2016) 197-208. [PubMed: 26802986]

[77]. Thompson W, Synapse elimination in neonatal rat muscle is sensitive to pattern of muscle use, Nature 302 (1983) 614-616. [PubMed: 6835395]

[78]. Thompson W, Jansen JK, The extent of sprouting of remaining motor units in partly denervated immature and adult rat soleus muscle, Neuroscience 2 (1977) 523-535. [PubMed: 917280]

[79]. Thompson W, Kuffler DP, Jansen JK, The effect of prolonged, reversible block of nerve impulses on the elimination of polyneuronal innervation of new-born rat skeletal muscle fibers, Neuroscience 4 (1979) 271-281. [PubMed: 424074]

[80]. Thompson WJ, Sutton LA, Riley DA, Fibre type composition of single motor units during synapse elimination in neonatal rat soleus muscle, Nature 309 (1984) 709-711. [PubMed: 6233493]

[81]. Tsien JZ, Linking Hebb's coincidence-detection to memory formation, Curr Opin Neurobiol 10 (2000) 266-273. [PubMed: 10753792]

[82]. Turney SG, Lichtman JW, Reversing the outcome of synapse elimination at developing neuromuscular junctions in vivo: evidence for synaptic competition and its mechanism, PLoS Biol 10 (2012) e1001352. [PubMed: 22745601]

[83]. Walsh MK, Lichtman JW, In vivo time-lapse imaging of synaptic takeover associated with naturally occurring synapse elimination, Neuron 37 (2003) 67-73. [PubMed: 12526773]

[84]. Wilton DK, Dissing-Olesen L, Stevens B, Neuron-Glia Signaling in Synapse Elimination, Annu Rev Neurosci 42 (2019) 107-127. [PubMed: 31283900]

[85]. Wyatt RM, Balice-Gordon RJ, Activity-dependent elimination of neuromuscular synapses, J Neurocytol 32 (2003) 777-794. [PubMed: 15034267]

[86]. Lee Y, Thompson W, The Vertebrate Neuromuscular Junction, Muscle: Fundamental Biology and Mechanisms of Disease, Academic Press, 2012, pp. 775-788. 


\section{Highlights}

- Neuromuscular synapse elimination is activity-driven

- More active motor neurons possess a competitive advantage

- Motor axons, Schwann cells and myofibers all actively participate in synapse elimination

- Neuromuscular activity-modulated effector mechanisms remain obscure 

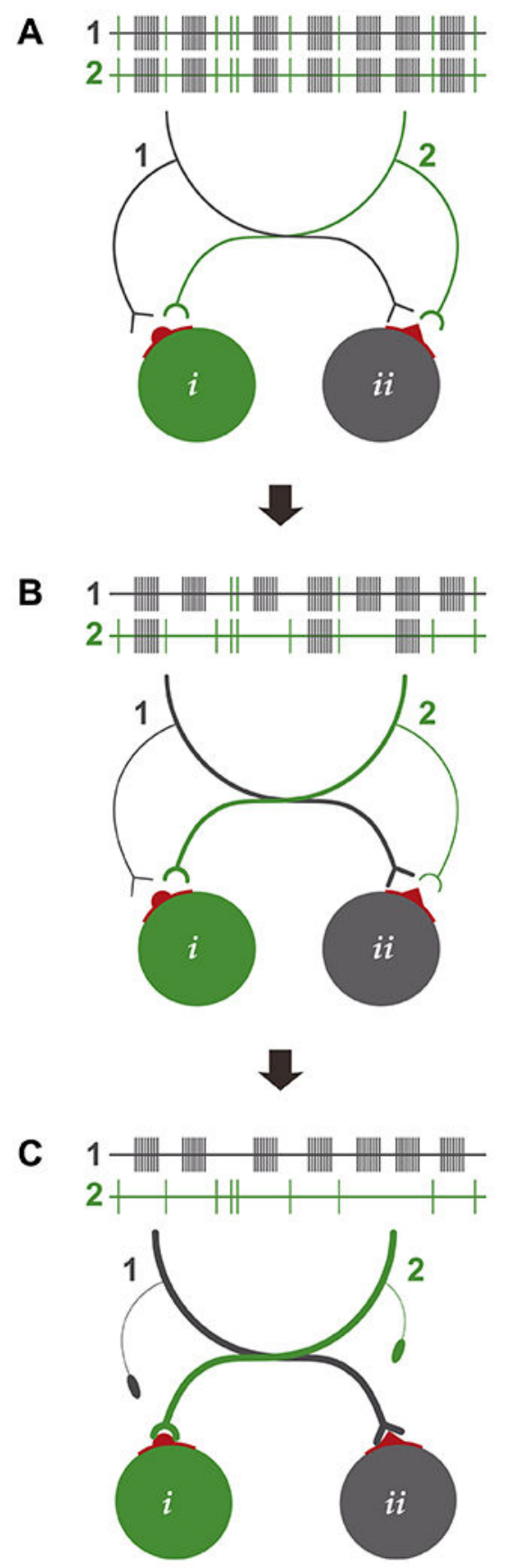

Figure 1.

Compatibility-based matching and elimination of potential motor axon-muscle fiber parings. Evidence suggests non-discriminate and pervasive innervation of all muscle fibers (i \& ii) during the initial formation of NMJs. (A) A significant portion of the motor neuron pool that innervates a common target muscle is electrically coupled and show a synchronized pattern of action potential discharges ( $\mathbf{1} \& \mathbf{2})$. (B) As postnatal maturation proceeds, electrical coupling between motor neurons start to dissipate and motor neurons begin showing signs of asynchronized activity patterns. In addition, muscle fiber types differentially express, at 
synaptic sites (red), surface recognition markers and/or attractive/repulsive guidance cues (round or pointed) recognized by converging motor axon terminals. Motor axons that express the appropriate receptors possess a competitive advantage. (C) During the latter stages of synapse elimination, motor neurons are no longer electrically coupled and allow matching of motor axons activity patterns with postsynaptic muscle fibers with compatible contractile kinetics. 

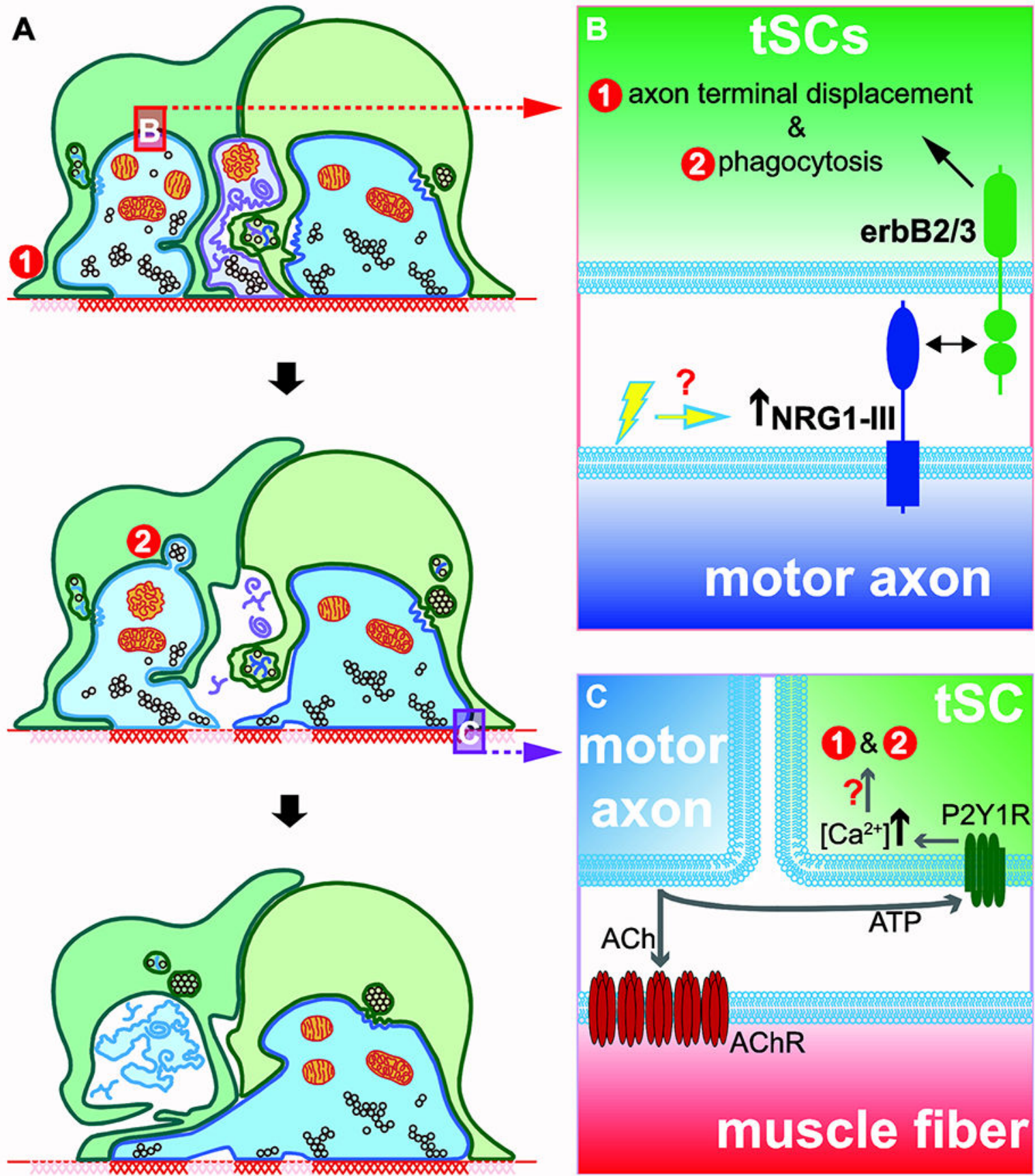

Figure 2.

Motor axon-derived molecules regulate synapse-pruning activities of tSCs at developing NMJs.

(A) tSCs engage in two motor input pruning activities: they compete for postsynaptic contact with the nerve and consume nerve terminals via phagocytosis. Concurrently, postsynaptic AChRs (red cross hatches) are eliminated from portions of the muscle membrane left vacant or occupied by tSCs and no longer receiving neurotransmission. Some recently abandoned postsynaptic sites are occupied on a stochastic basis by sprouts of nearby nerve terminals, 
and the process continues until a single motor input remains (see [82]). (B,C) Motor axon terminal influences tSC behaviors in two ways: presentation of NRG1-III on axolemma (red inset in $\mathbf{A}$, enlarged in $\mathbf{B}$ ) and neurotransmission (green inset in $\mathbf{A}$, enlarged in $\mathbf{C}$ ). (B) Axon-tethered NRG1-III enhances (1) displacement and (2) phagocytosis of nerve terminals by tSCs. NRG1-III levels may be modulated by motor neuron activity. (C) During neurotransmission, ATP is coreleased with ACh from synaptic vesicles. ATP binds and activates P2Y1R purinergic receptors and leads to an increase in $\mathrm{Ca}^{2+}$ concentration in tSC soma. Downstream effectors that affect synapse elimination remains obscure. Increased cytoplasmic $\mathrm{Ca}^{2+}$ may lead to enhanced phagocytosis and displacement of nerve terminals by tSCs. 